\title{
Solar PV Planning Toward Sustainable Development in Chile: Challenges and Recommendations
}

\author{
Shahriyar Nasirov $^{1} \quad$ Carlos Silva $^{2} \quad$ Claudio Agostini $^{3}$
}

\begin{abstract}
In the last decade, the importance of solar energy sources in Chile has increased significantly as energy dependence raises and concerns regarding climate change grow, posing an important threat to its economy. The Chilean government recognises that exploiting its abundant potential of solar energy could be an important opportunity to address stable economic growth, energy security, and fulfil environmental goals. Recent developments toward sustainable solar PV planning have accelerated the growth process and investment opportunities in the field. However, to date, numerous policy challenges still exist. This paper studies solar PV planning in Chile, pointing on recent developments and remaining challenges. It also gives important recommendations for effectively addressing these challenges.
\end{abstract}

Keywords: Solar energy, Sustainability, Planning, Chile

\footnotetext{
${ }^{1}$ Universidad Adolfo Ibañez, Chile. Email: shahriyar.nasirov@uai.cl

2 Universidad Adolfo Ibañez, Chile. Email: c.silva@uai.cl

${ }^{3}$ *Corresponding author. Universidad Adolfo Ibañez, Chile. Email: claudio.agostini@uai.cl; Tel: +56 (2) 23311130
} 


\section{Introduction}

Over the last years, Chile has become one of the leading countries in the region of South America with regard to institutional and political stability, economic growth and market reforms. The Chilean economy has experienced an exceptional performance in terms of economic indicators thanks to its stable economic progress (See table 1). It is certainly worthy of note that Chile has implemented its reforms in such a way that it has reduced its poverty level from $40 \%$ down to $13 \%$ in two decades, allowing Chile to become the only member of the Organization of Economic Cooperation and Development (OECD) in South America [1].

Table 1: Major changes between 1990 and 2013 years in Chile [2] and [3].

\begin{tabular}{lll}
\hline \multicolumn{1}{c}{ Indicator } & \multicolumn{1}{c}{} \\
\cline { 2 - 3 } & \multicolumn{1}{c}{1990} & \multicolumn{1}{c}{$2011-2013$} \\
\hline GDP (US\$ of 2014) & 31 billion & 277 billion (2013) \\
GDP per capita (US\$ of 2014) & 2,388 & $15,573(2013)$ \\
Foreign direct investment, net inflows (US\$ of 2014) & 0.66 billion & 20.3 billion (2013) \\
Energy production (kton) & 7,927 & $9,760(2012)$ \\
Energy use (kton) & 14,009 & $32,720(2012)$ \\
Energy self-sufficiency (\% of energy use) & $65 \%$ & $30 \%(2012)$ \\
Electricity consumption (kWh per capita) & 1,243 & $3,568(2011)$ \\
Installed electricity capacity (MW) & 4,418 & $18,465(2013)$ \\
CO2 emissions (kton) & 34,143 & $72,258(2011)$ \\
CO2 emissions (metric ton per capita) & 2.6 & $4.7(2011)$ \\
\hline
\end{tabular}

This dynamism of the economy, including the significant improvement of well being of Chile's population, has led to a double boost of electricity demand. This positioned Chile as the country with the highest consumption per capita in Latin America with $3,568 \mathrm{kWh}$, well ahead of largest countries like Argentina (2,967 kWh), Brazil $(2,438$ $\mathrm{kWh})$ and Colombia $(1,123 \mathrm{kWh})$ [2]. As Chile's economy continues to grow, it is expected that electricity demand will increase from under 65,000 MWh in 2012 to over 100,000 MWh by 2020 [3] and [4]. To sustain this growth, the country will have to add over 8,000 MW of new generation capacity by 2020 in order to meet the expected expansion in demand. The new generation capacity will provide energy to the country's economic structure, where $33 \%$ of the total electricity generated is consumed by the mining sector, while other industries consume $28 \%$, and the residential and commercial 
sectors consume the remaining $27 \%$ [5]. Most of the demand from the mining sector is concentrated in the northern part of the country, where there are no significant rivers, forcing the development of many thermoelectric plants (99\% of the electrical generation of the Northern Interconnected Power System ${ }^{4}$ (SING) is thermoelectric). This segment of the generation market is subjected to fuel-price volatilities and also has major global and local impacts on the environment. In fact, as table 1 shows, the level of $\mathrm{CO} 2$ emissions has increased more than twice between 1990 and 2011, driven mostly by the new thermal energy. The increase in energy consumption has also led to a strong dependence from external sources to supply the primary energy needs. In fact, in 1990 , the country had level of energy self-sufficiency over $65 \%$, mostly using hydroelectricity, which is a local, abundant and clean resource in the south [6]. The rest accounted mainly from coal and oil. Regrettably, as of today, Chile`s self-sufficiency has deteriorated to between $30 \%$ and $35 \%$, placing the country well below some other countries in South America, such as Brazil where the self-sufficiency exceeds $90 \%$, Colombia with over 95\%, and Argentina with around 80\% [7].

Due to the growing energy demand, the increasing dependence on imported energy sources, the environmental concerns, and the rising costs of fossil fuel prices, the Chilean government considers of strategic interest to push for energy diversification. To advance in this matter, however, the government has to decide what energy sources and technologies need to be prioritized to provide energy security, environmental sustainability at a competitive cost. In this scenario, solar PV is positioning itself as a good source of clean and competitive energy, which can have a major impact on the future energy diversification of countries with high solar resources. This paper examines the strategic and important role that solar PV can play as an energy alternative to secure sustainable development in Chile, focusing on recent developments and remaining challenges for its growth planning. It also gives important recommendations for effectively addressing these challenges. The rests of the paper is organized as follows. Section 2 presents global trends in solar energy applications. Section 3 highlights major hidden benefits of solar PV energy utilization in Chile. Section 4 describes current status in solar PV energy applications in Chile. Section 5 examines key challenges for solar PV energy planning while Section 6 provides

\footnotetext{
${ }^{4}$ Chile's power sector is divided into two separate systems, SING and SIC. The SIC system has hydro-thermal generation and covers the central and southern regions of the country, including the main consumption centres around the capital, Santiago. The SING has a thermal-based generation and provides primary electricity demands for mining and mineral industries in the northern part of the country.
} 
important policy recommendations. Finally, concluding remarks are provided in Section 7.

\section{Global Trends in Solar Energy Applications}

In recent years, solar power generation systems have gained significant attention as a key alternative to solve the energy problems in various countries. The solar PV industry grew at an unprecedented rate globally during the last decade, reaching almost 139 GW capacities in 2013 (See Figure 1). Just in 2013, 39 GW of solar PV capacity was added. Furthermore, a $690 \mathrm{GW}$ capacity is expected to be installed across the world by 2035 [8]. As seen in Figure 1, almost 98 \% of all PV capacity has been installed since the beginning of 2004. PV capacity growth in 2013 was mostly driven by the top three installers China, Japan, and the United States. The same year, Asia surpassed the market leader for a decade, Europe, and became the largest regional market in the world. Asia has installed $22.7 \mathrm{GW}$ to end 2013 with almost $42 \mathrm{GW}$ of solar PV in operation (See figure 2). China alone made almost one-third of global installations, adding a record $12.9 \mathrm{GW}$ to nearly triple its capacity to approximately $20 \mathrm{GW}$. As a result of this huge capacity additions within a short time of period, the electricity system in China experienced challenges in connection with grid connectivity and operation (Haugwitz [9]). Beyond Asia, about 16.7 GW was summed worldwide, primarily in the EU (about $10.4 \mathrm{GW}$ ) and North America (5.4 GW), led by the United States-the third largest country-level market in 2013.

Figure 1: Solar PV Total Global Capacity, 2004-2013 [8]

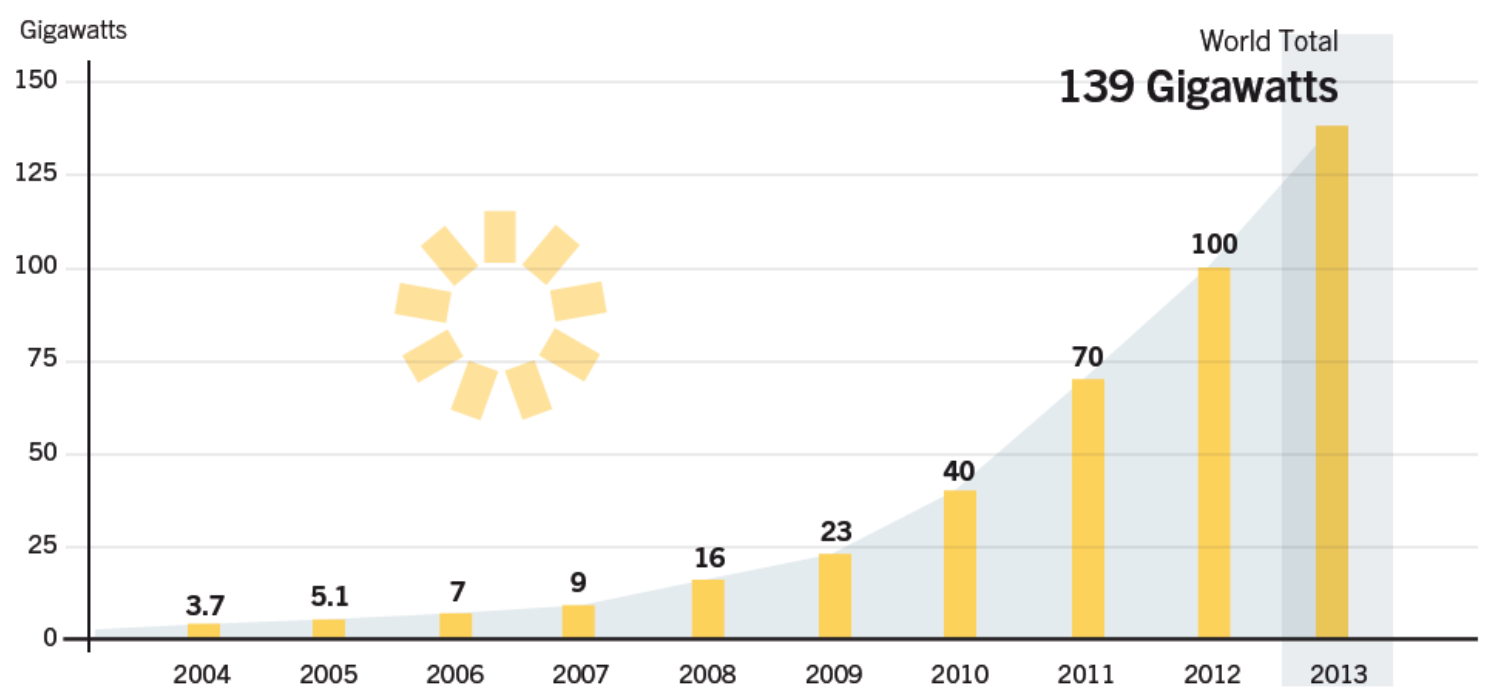

Sources: Renewables 2014, Global Status Report 


\section{Figure 2: Solar PV Capacity and Additions, Top Ten Countries, 2013 [8]}

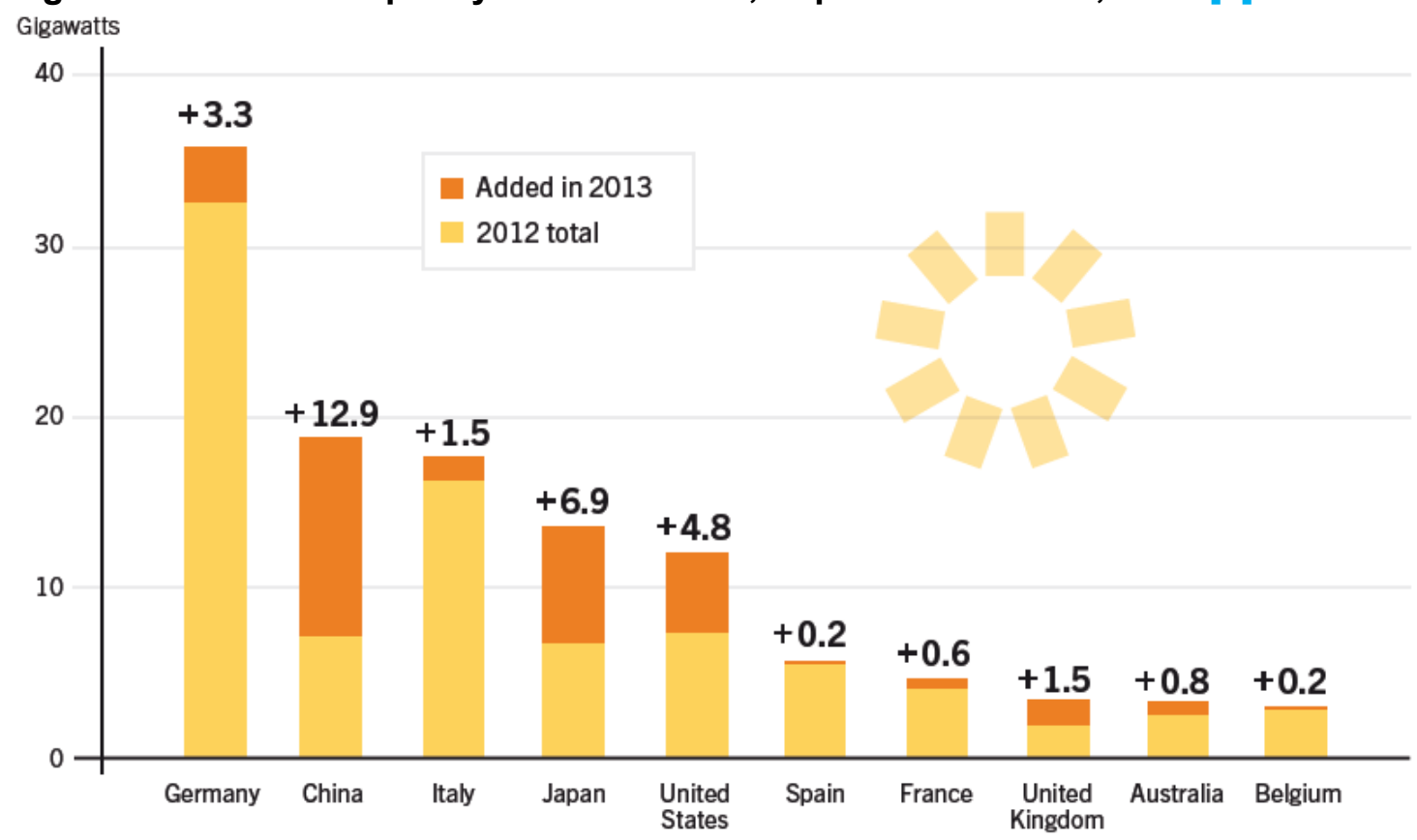

Sources: Renewables 2014, Global Status Report

A review of the literature on solar PV development reveals that rapid expansions of these technologies are mainly due to technological advancements and different policy support mechanisms ([10] and [11]). The impact of technological advancements in this trend has been significant as it drove solar panel prices down from $\$ 4.15 /$ watt in 1996 to $\$ 0.56 /$ watt in 2013 [8]. A large number of governments have supported solar energy development through a broad range of fiscal, regulatory, market and other instruments. A number of studies describe in-depth analysis of various policy instruments designed to promote solar energy [12-14]. Among the existing instruments, FIT $^{5}$ (Feed-in Tariff) and RPS $^{6}$ (Renewable Portfolio Standards) models are extensively implemented. Both models have their own pros and cons in achieving specific objectives in relation to development of PV. There is a large literature detailing the experience with RPS and RPS options for solar energy and it is important to highlight some of its results. Wiser et al. [15] and Rowlands [16] confirm that overreliance on RPS may not help the diversity of renewable resources in the energy matrix. Timilsina et al. [11] also studied different applications of FIT and RPS programs identifying advantages and disadvantages in solar PV applications. Their results show that although FIT programs help to guarantee

\footnotetext{
${ }^{5}$ FIT is an electricity rate paid for generation that typically offers a guarantee of: payments to project owners for total $\mathrm{kWh}$ of renewable electricity produced; access to the grid; and stable, long-term contracts (15-20 years).

${ }^{6}$ RPS sets penetration targets for renewable energy in total electricity generation mix at the national or state/provincial levels. To achieve the targets, electricity suppliers (e.g., utilities, distributors) are obligatorily required to provide certain percentage of their electricity supply coming from renewable energy sources.
} 
a fixed return on investments, they do not help in reducing high up-front costs of solar PV. On the contrary, Frondel et al. [17] harshly criticizes FIT schemes, particularly for the case of Germany, arguing that the scheme failed to accomplish its promises on emissions reductions, employment, energy security, or technological innovation while resulting in massive expenditures.

Chile, as its major regulatory support mechanism regarding the expansion of renewable energy, has adopted a RPS model for energy from generators with the goal of reaching $20 \%$ from RES into their energy mix by 2025 . Considering Chile's liberal economic tradition, the RPS fits the structure of its electricity system and energy policy. However, as the evidence in the literature shows, the situation is still challenging and there is uncertainty in terms of whether these policies are going to be an effective tool for the diffusion of solar PV technologies in the country or not.

\section{Hidden Benefits of Solar Energy Utilization in Chile}

Even as the costs of solar power continue to decline, there is still a widespread perception from the public and many policymakers that solar energy is "too expensive". As a result of this perception, many policymakers conclude that the country should not invest in solar energy because energy prices would increase. Under these circumstances, it is clear that some potential large social value of solar energy is missed by traditional analysis. For this reason, we believe that it is worth to discuss and explicitly consider several other benefits of solar energy that, even though they might be difficult to measure, are often neglected. Based on a detailed analysis provided by the International Energy Agency [18], we discuss three main benefits of solar energy that are especially relevant in the case of Chile: (1) to provide secure and sustainable energy, (2) to support economic development, and (3) to address climate change and environmental concerns.

\section{- Secure and Sustainable Energy}

Historically, Chile has experienced several energy crises in the past two decades due to a lack of a reliable energy matrix. Until the 1990s, hydroelectricity was the main source of electricity generation and considered to be almost the sole solution to the country's growing energy needs. However, every time the country faced a draught the security of supply was a stake and there were even periods of blackouts and rationing [19-21]. 
A decade later, Chile switched rapidly to depend on Argentina's natural gas. The low cost gas made combined-cycle plants attractive compared to other traditional energy sources, including hydro and coal plants [22]. As a consequence, the generating companies invested heavily in natural gas infrastructure, including building four pipelines from Argentina, a brand new gas distribution network and a half a dozen combined-cycle-gas-fired power plants. Investment in new natural gas infrastructure sum up to around US\$4 billion [23]. However, starting in 2004, the Argentinean government started to restrict gas exports to Chile in order to ease its own domestic gas shortages. Shortly after, Argentina's natural gas supply became less and less reliable to the point of practically halting the gas flow. This situation forced generators to import expensive diesel oil and the government promoted the construction of LNG facilities to compensate these changes.

Over the last five years (2009-2013), the situation has become even worse in terms of meeting domestic energy needs. Energy has probably become the main obstacle for the development of the Chilean copper industry, as the cost of energy now represents about $20 \%$ of the total cost of mining [24]. Chile has the world's largest copper industry, with a supply of $30 \%$ of global production. In addition, mining is a key sector of the Chilean economy representing nearly half of the country's total exports and is located in the rich solar zone of the country. Mining consumes an estimated $90 \%$ of all electricity in the SING and around $38 \%$ of the total electricity demand in the country. Also, as the mining industry grows, the demand for energy is expected to follow at a rate of at least $5 \%$ per year for the next decades [24]. According to the projections of the National Energy Commission (CNE), $60 \%$ of the energy demand growth in the country will come from the mining sector [25]. Moreover, the high dependency on external fossil fuels and growing demand for energy have pushed up the marginal costs from energy generation in both systems (SING and SIC) of the Chilean market, a situation that has worsen up as international fuel prices have increase significantly. Currently, electricity prices in Chile are among the highest in Latin America and higher than the OECD average prices for electricity, ranging from \$150/MWh to \$250/MWh [26].

The successive energy crises have taught a valuable lesson and now the country is more concerned about the degree of energy diversification, understanding its important role for the security of the system [27]. In this scenario, adding PV sources to the energy mix can be an important opportunity to contribute to the country's energy diversification strategy. In particularly, it can help to reduce dependency from external 
fossil fuel sources, especially in the SING, where supply essentially serves mining companies and other industrial users.

\section{- Economic Development}

Solar photovoltaic (PV) remains one of the most dynamic renewable energy technologies in terms of its contributions to the economic development. China's recent success in development of solar PV technologies proves that emerging economies like Chile can also use green growth strategies in the promotion of a more sustainable growth overall [18]. Over the past decade, the manufacturing industry in solar PV has experienced tremendous growth. The module production has doubled in Asia accounting for $87 \%$ of global production (up from $85 \%$ in 2012), with China producing $67 \%$ of the world total in 2013 [8]. Manufacturing employment in solar PV has also led to the highest net employment effects among the other renewable technologies. According to the estimations of IRENA, there were as many as 2.3 million PV jobs worldwide in 2013, up from 1.4 million in 2012 [28].

Strengthening the economy in rural areas has also been a rationale for using solar PV technologies in several countries. Due to their distance to the power systems and their low populations, network extension is typically not a viable economic option for these communities. In isolated rural areas with lack of access to electricity, grid extensions are often not cost-effective. Therefore, off-grid solar PV technologies can provide a sustainable and cost-effective alternative to the other alternatives that would be typically deployed in such areas. Chile has more than 3,500 isolated rural communities with no access to energy networks and many of them also lack access to roads and infrastructure to maintain the flow of fossil fuels [29]. Deploying solar PV energy technologies can deliver a cost-effective and an environmentally friendly solution, which can increase daily productivity and improve quality of life in these rural communities.

\section{- $\quad$ Lower Emissions to the Environment}

The other important benefit of solar power utilization lies on the environmental advantage from producing less $\mathrm{CO} 2$ emissions than fossil fuel sources (See Figure 3). The numbers presented in Figure 3 are based on the lifecycle assessment and report the $\mathrm{CO} 2$ emissions emitted by various generation technologies over their life cycle. As shown, solar PV technologies offer as favorable environmental conditions as hydropower, wind, geothermal and nuclear power plants and its environmental loads 
are very small in comparison with fossil fuels, including natural gas and coal. While the operation of a solar PV plant has a small environmental load, the main burden is associated with the panels' life cycle, specifically due to the material manufacturing, transportation and power plant construction.

Figure 3: Life-cycle CO2 emissions of power-generating technologies [18]

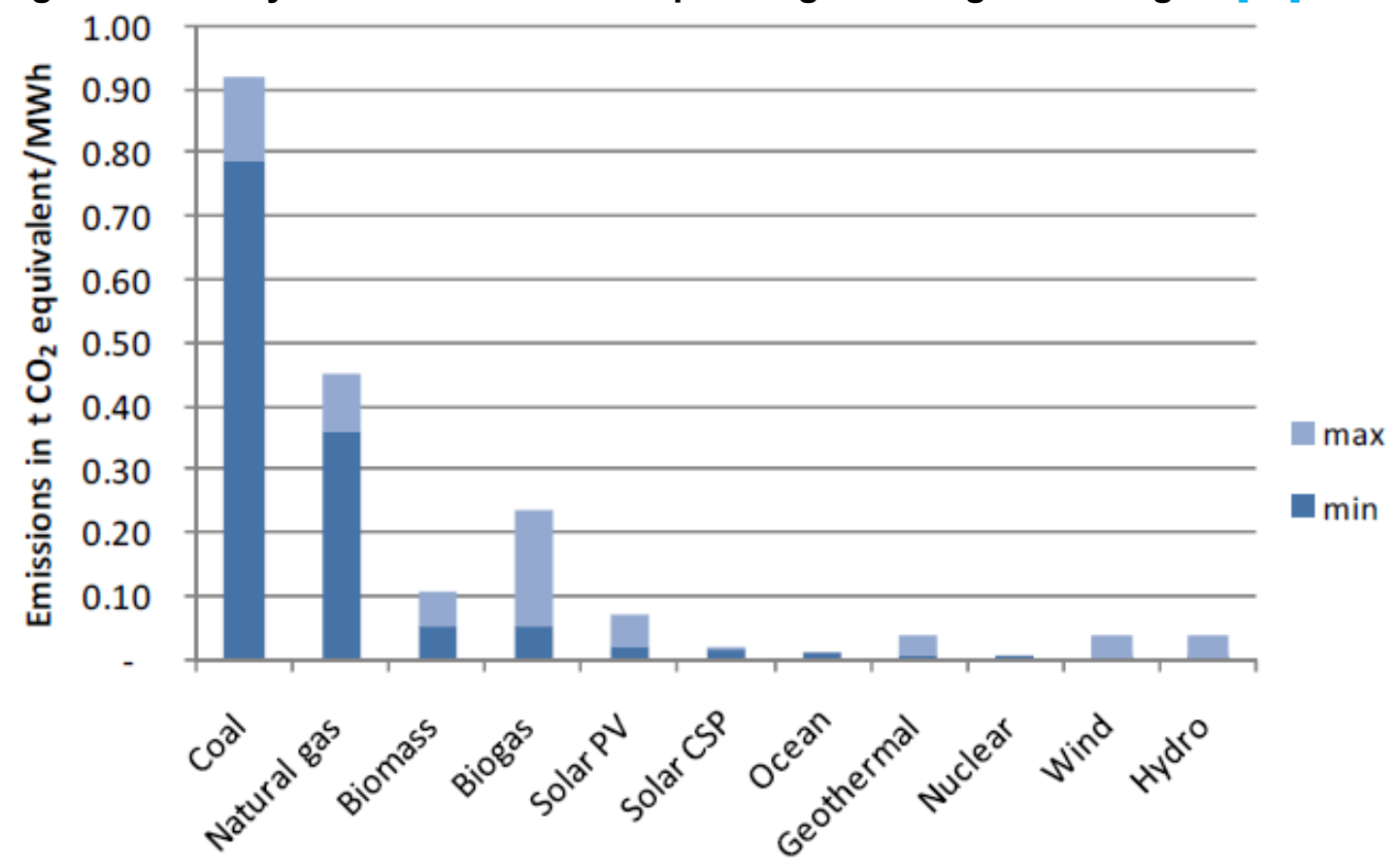

\section{Current Status in Solar Energy Applications in Chile}

The development of PV solar energy in Chile is particularly attractive because the country is endowed with one of the most consistently high solar potentials in the world. The Atacama Desert, in the north of the country, offers the best conditions for generating PV solar energy with high solar radiation, low humidity and almost 356 days of clear skies [30]. The annual daily horizontal solar irradiation in any region of Chile north of the Maule region (300 km south of Santiago) (3000-4200 kWh/m2) is significantly higher than Germany $(900-1250 \mathrm{kWh} / \mathrm{m} 2)$, France $(900-1650 \mathrm{kWh} / \mathrm{m} 2)$ and Spain (1200-1850 kWh/m2) [31].

In existing legislations, the promotion and use of solar PV technologies is included within renewable energy policies, with no specific legislation dealing with PV technology alone [32]. Legal basis concerning legislations regarding promotions of renewable policies commenced in Chile when Congress approved in 2005 what it was called "Short Law I", which establishes key incentives for the development of smallscale energy projects for the first time since the liberalization of the market. The 
legislation allowed all small power producers $(<9 \mathrm{MW})$ to participate in the spot market and entitled them to have a simplified commercial treatment for trading. As part of the new regulation, small-scale energy projects are guaranteed open access to the distribution networks and exempted of charges from the usage of the trunk system. For the first time in 2008, the government took an important step forward by approving a RPS scheme that introduced the obligation for companies to generate at least $10 \%$ of their electricity from non-conventional renewable energy sources by 2024 .

In 2013, based on an estimation of new renewable capacity requirements of $6,500 \mathrm{GW}$ for the next decade, the Chilean government established a new incentive by doubling its renewable-energy target from the previous goal of $10 \%$ by 2024 to $20 \%$ by 2025 . The change was established in a new law approved by Congress known as Law 20/25 that, in addition, introduced an auction mechanism to award 10-year power contracts to complete any part of the established quota that has not been met. The auctions will be under the supervision of the Ministry of Energy with the principle of technological neutrality. Non-compliance with the law results in a fine of approximately $28 \mathrm{US} \$ / \mathrm{MWh}$ for every MWh below the quota. During the following three years, if the non-compliance is repeated, the fine raises to 42 US\$/MWh [33].

Over the last years and through several different institutions, the Chilean government has introduced several other incentive mechanisms for supporting and promoting of PV technologies in the country. CORFO is governmental agency dependent of the Ministry of Economy, which is responsible of facilitating financial support of companies through innovation, entrepreneurship and technological transfers. Through CORFO the government has established various instruments to indirectly promote the use of PV technology, including low-interest loans, capital guarantee and risk capital funds and innovation study grants. The Center for Renewable Energy (CER) is considered to be another key institution for facilitating the development of the PV technologies in Chile. The major mission of CER is to coordinate public and private initiatives, to promote and advance $\mathrm{PV}$ projects, and to provide and make valuable information available to everyone. CONICYT, an agency from the Ministry of Education, is responsible for promoting the creation of human capital and establishing the country's scientific and technological base. With the aim of strengthening scientific and technological foundations on solar energy, CONICYT is financing the Solar Energy Research Center (SERC-Chile), a specialized scientific center that aims to build a solid base of scientific knowledge and to promote programs for the transfer of PV technology. 
Over the last two years, as a result of these new public policies and incentives, Solar PV technologies have started to play an increasing role in the energy matrix of the country. Table 2 details the evolution of solar PV and other Renewable Energy Sources (RES) either under operation/construction or under evaluation/approval of the Environmental Impact Evaluation System (SEIA).

Table 2: Status of RES in Chile [34]

\begin{tabular}{l|cccc}
\hline $\begin{array}{c}\text { Technology } \\
\text { SIC+SING }\end{array}$ & $\begin{array}{c}\text { Operating } \\
\text { (MW) }\end{array}$ & $\begin{array}{c}\text { Under } \\
\text { construction } \\
(\mathbf{M W})\end{array}$ & $\begin{array}{c}\text { Approved } \\
\text { SEIA (MW) }\end{array}$ & $\begin{array}{c}\text { Under } \\
\text { evaluation } \\
\text { SEIA (MW) }\end{array}$ \\
\hline $\begin{array}{l}\text { Large hydro run } \\
\text { of river }\end{array}$ & 2,307 & 80 & 1,690 & 1,376 \\
\hline Hydro dams & 4,019 & 0 & 2,750 & 0 \\
\hline Small Hydro & 340 & 51 & 290 & 183 \\
\hline Solar PV & $\mathbf{1 8 4}$ & $\mathbf{4 4 1}$ & $\mathbf{5 , 8 0 9}$ & $\mathbf{4 , 1 5 5}$ \\
\hline Solar CSP & 0 & 100 & 760 & 0 \\
\hline Biomass & 461 & 22 & 74 & 66 \\
\hline Biogas & 43 & 0 & 0 & 8 \\
\hline Wind & 682 & 154 & 4,542 & 2,099 \\
\hline Geothermal & 0 & 0 & 120 & 0 \\
\hline
\end{tabular}

As shown in Table 2, $5.800 \mathrm{MW}$ of PV projects with environmental approval, most of them side-lined are waiting to enter to the grid in Chile and 4,155 are under evaluation. These numbers show that, potentially, there might be a promising future for the development of PV technologies. However, despite the improvements in many areas, to date, the small number of PV projects actually operating show that numerous policy challenges still exist and that maybe the country has not taken the most consistent approach to ensure the diffusion of PV technologies. In the following section, we analyze several challenges for solar PV energy planning in Chile.

\section{Challenges for Solar PV Energy Planning in Chile}

Based on the data and information collected from agency reports, company press releases, and academic publications, as well as semi-structured face-to-face interviews with experts specialized in solar PV deployment, we argue that the key challenges for solar energy planning in Chile are mostly associated with market and institutional level, resource management and transmission planning. 


\subsection{Market and Institutional System}

Over the last decades, Chile has introduced several market liberalization and privatization reforms in the electricity industry that led to major changes in the energy market structure and its institutional framework [35]. As a result, a regulated spot market was established and the prices were regulated based on the marginal costs of generators in the system and the associated least cost of dispatch. Chile's electricity reforms have been adopted as a highly successful pattern in a developing country and a model for other privatization cases in Latin and America and around the world [36].

Chile's energy market structure is characterized by a greater private sector prominence and the institutional framework in the electricity sector has been adjusting incrementally to developments in the sector without any major changes in its principal structure. However, an assessment of the Chilean existing institutional and market structure reveals that there are serious limitations to entry for new firms, including those seeking to implement innovative projects such as small-scale solar and other alternative renewable energy projects [37].

The main criticisms to the reforming history of Chile are based on the market structure that appeared from privatization, which consists of an important degree of vertical integration [38] and a highly concentrated market. As of today, the market shares of just three generating companies, Endesa, AES Gener and Colbún, account for approximately two thirds of Chile's installed capacity [37]. Even though the privatization of the two existing state owned companies, Endesa and Chilectra, sought to improve productive efficiency and generate a strong competitive market, the new privtaized companies can still exercise market power. In fact, Arellano [39] found that if an unregulated spot market were implemented in Chile prices could easily go up far above competitive levels as generators, in particular Endesa, the largest generator, would exercise unilateral market power. So, the old state-owned, vertically integrated companies have not been split in a way that creates a truly competitive marke. Instead, the market remains concentrated in the hand of a few companies generating barriers to the entry of potential small/middle scale investors.

In addition to market structure shortcomings, the current institutional structure in Chile is incompatible with a market able to incorporate the new prioritized technologies due to inadequate national planning [40]. The absence of profound improvements in the State's management, and in the working of institutions in charge of regulating and 
monitoring the sector, do not guarantee that the Chilean government may reach its energy targets set to diversify energy matrix through prioritizing solar PV energy technologies. In practice, State's weak regulatory and planning roles in the electricity sector leave government authorities (at the national, regional and local levels) with little ability to shape the electricity sector effectively [37]. The functioning of the four major institutions in the sector $\left(\mathrm{CNE}^{7}, \mathrm{CDEC}(\mathrm{SING} \text { and } \mathrm{SIC})^{8}, \mathrm{SEC}^{9}\right.$, and the Ministry of the Energy) generates inefficiencies, resulting in high litigation costs, certain randomness and biasness in their decisions and difficulty in the coordination of policies where interests are shared. The major constraint that prevents these institutions to operate efficiently in regulating the market is their weak technical capacities [40]. Technical weaknesses are due to reasons like no independence from political power, no independent and sufficient budgeting and low salaries. For instance, a similar concern arises with the governance of the system operators (CDEC) in Chile. So, the two system operators were originally highly influenced by the largest generators and the transmission companies in each system.

\subsection{Resource Management Structure}

Solar PV projects in Chile often face many challenges during the planning process due to concerns on environmental and social impact assessments and granting concessions. The key regulatory mechanism used by a planning institution is impact assessments (IA) [42-44]. Some of the most commonly used impact assessments are the Environmental Impact Assessment (EIA) and the Strategic Environmental Assessment (SEA). The main objective of these assessments is to ensure that the development of a project only proceeds in an acceptable manner [42]. In Chile, regardless of the type of the resource to be exploited, every energy project has to obtain an approval from the Environmental Impact Assessment System (SEIA) in order to prove that it does not produce damage or represents a hazard to the environment [33]. An SEIA is compulsory in any project (isolated or grid-connected) with installations over $3 \mathrm{MW}$ and the need of transmission grid [45]. Chile's environmental regulatory framework is based on the Environment Law, 19,300, which was enacted in 1994 and was lastly reformed by Law 20,417 in 2010 . According to the environmental law, project representatives need to choose one of two routes to submit the initiatives to SEIA. The first route is to file an Environmental Impact Declaration (DIA) and it is considered to be the most simplified procedure as it is applicable to those projects that do not generate

\footnotetext{
${ }^{7}$ National Energy Commission

8 The Economic Load Dispatching Centre (market operators)

${ }^{9}$ The Superintendence for Electricity and Fuels
} 
any environmental impacts indicated in the Law. The second route considers projects generating one or more environmental impact, and requires filing an Environmental Impact Study (EIA), which is more complex and demanding. In addition, EIA requires baseline development, analyses of impact, and mitigation and compensation measures for the projects. Even though the Chilean regulatory system requires explicit consideration of the possible environmental and social impacts of each project, there are deficiencies in the assessment framework to measure these impacts properly [37]. The lack of citizen participation or discussions in SEIA decisions, for example, is often recognized as one of the main sources of political and legal challenges. In practice, project developers fail to take into account the full range of costs and benefits on local communities, resource management goals, and other policy objectives when they design EIA/DIA proposals.

Obtaining concession rights for extensive territories is another critical issue for the development of the different types of renewable energy projects. In the development process, project developers face a numerous of regional regulations and, at times, complex negotiations with landowners over project sites. One of the primary bottlenecks is related to the troublesome process to obtain property rights (ownership or concession) for using land belonging to the state of Chile. Chile's regulatory framework regarding concessions is based on the Concession Law 1939, which was enacted in 1977 and was lastly modified by Law 19.833 in 2002 [32]. The main problem is that the law does not set robust and transparent methods for a project evaluation, which result in discretionary decisions for granting concessions. At this time, submitting an application to the Ministry of National Assets, which is in charge of managing all land from the state, delays the start of a project several months or even years. Besides, Chile's concession system lacks regulations and standards to provide an important guide in navigating difficult issues related to the status and ownership of other resources within the boundaries of the concession. On the other hand, if the land is privately owned, this could also take a long time, because of troublesome negotiations with many owners. For instance, over the last decades, the concessions granted to mining interests have soared tremendously in Chile. This, in turn, has intensified the different conflict of interests with mining concessions and the users of agricultural lands, all of which impedes construction of medium-sized and large solar PV plants.

\subsection{Transmission Investment Planning}

To take advantage of different kind of renewable resources, particularly solar sources, the transmission system needs to be reinforced and expanded in Chile. As of 2014, the 
total capacity of only approved PV solar projects by the Chilean environmental approval body, SEA, has surpassed 5,800 MW. This amount is staggering, considering that the country's solar capacity recently connected to the grid adds up to only $184 \mathrm{MW}$ (see Table 2). Due to the geographic characteristics of Chile, $87 \%$ of the SEA approved PV projects are located in northern Chile, waiting to connect to Chile's northern grid - SING. This grid has a total of $4,600 \mathrm{MW}$ generating capacity, which is even smaller than the expected PV capacity inflow. At a glance, having such a volume of projects with environmental approval seems a significant breakthrough for the current nascent stage of the Chilean solar PV market. However, some concerns have been raised regarding how much of this capacity could be achieved in the absence of a robust transmission system. The construction of the additional needed capacity in the time frame required poses a significant challenge for solar PV projects. Under these circumstances, connecting the SEA approved PV projects within the average timeframes would require a grid expansion in the SING to grow just for solar projects by $8 \%-12 \%$ per year.

The existing transmission sector in Chile has been considered a natural monopoly and revenues are regulated. Traditionally it was designed to transport electricity from conventional incumbent power generators to consumers within a local market. According to the existing regulation, generation companies share the costs of electricity transmission with consumers in such a way that generators pay $80 \%$ and consumers pay the other $20 \%$ [47]. This setup gives to generation companies an advantage to have a significant influence over the transmission subsector. Incumbent generators have an interest in keeping transmission costs low, blocking the entry of sufficient investment in the transmission subsector. As a result, many nascent projects in Chile are paralyzed due to a lack of interconnection.

The "Short Law 1" of 2004 was the first public policy effort to stimulate more competition and investment in the transmission sector. It defined new procedures to calculate transmission tolls and created a cooperative planning process to expand the trunk transmission system [32]. According to this regulation, the system operator CDEC prepares the main grid's transmission expansion plan on a yearly basis. Based on the current market conditions, the CNE identifies the referential transmission projects for the next four years [48]. Although this regulation is supposed to lead to improved transmission planning and investment, so far it has not been successful in doing so. For instance, the expansion process on new grid lines can be delayed up to 42 months due to legal requirements, bureaucracy and communities' opposition [46]. 


\section{Policy Recommendations for Solar PV Planning in Chile}

We argue that the growth of solar PV industry in Chile needs to be driven by an effective sustainable policy planning. In order to promote the development of solar energy in Chile, a concrete set of best practices are required for a long enough period to attract investments, resulting in the development of a mature industry. In the following sub-sections, we highlight the potential improvements for challenges in the existing solar PV planning conditions in Chile and propose alternative mitigation options.

\subsection{Political Priorities for Solar PV Energy}

Chile, as its major regulatory support mechanism regarding the expansion of renewable energy, has adopted a RPS scheme for energy from generators to incorporate a $20 \%$ by 2025 from RES into their energy mix. As discussed in Section 2, the result of RPSs may produce a wide array of distortions in the market [11-16]. Even in the opinion of some experts, the punishment mechanism for non-compliance with the obligations in Chile seems significantly soft, compare with the marginal costs in the market, it is sometimes cheaper for some generation technologies not to comply with the quota and pay the fine than to invest in RES [50]. In addition, due to a lack of differentiation between technology sectors in the RPSs, the long-term goals for development of relatively expensive technologies, particularly solar PV may not be attained. Generators may be encouraged to fulfill the quota through investing in the cheapest renewable technologies in the short-term. In order to avoid this dynamic inefficiency, instead of making drastic changes in the support system it would make more sense to introduce some specific standards for solar energy technologies and increase the fines to the correct level in case of non-compliance with the legal obligations. For instance, a similar experience of an RPS model with specified standards for solar energy has been implemented in New Jersey before. The RPS legislation in New Jersey requires a total of $20.38 \%$ of its electricity to come from renewables by 2021. In addition, 2,518 GWh electricity must be generated from solar technologies in 2021 and 5316 GWh in 2026 [49]. Similarly, the RPS legislation in Nevada requires that $6 \%$ must be generated from solar power by 2015 .

However, the target setting for solar PV technologies also needs to be realistic, quantified and to be matched with the corresponding allocation of resources and financial commitments for achieving the targets. It would be important to set the targets 
basing on short, middle and long-term objectives and actions and set up tracking mechanisms for review, as well as establishing additional measures where there is a possibility of a falling off. Furthermore, an incremental and phased approach to achieving targets may be adopted. For instance, more recently, India has established the National Solar Mission setting a target to develop 20,000 MW of solar energy by 2022 [51]. This target needs to be achieved in three phases: Phase 1 by early 2013; Phase 2 and 3 by 2017 and 2022 respectively.

\subsection{Modernization of the Institutional Conditions}

Even though, having integrated solar energy political objectives seems to be critical to attaining positive outcomes in Chile and should be a priority, the implementation of these political priorities highly depends on the modernization and successful coordination of the relevant regulatory institutions. Despite a good performance of the regulatory experience in Chile, much remains to be done to modernize the regulatory institutional conditions. Not only it is crucial to provide the regulatory institutions with technical and financial capacity, but they also require economic and political independence from ministries. The institutional capacity of the regulatory agents must be strengthened so that they can solve ambiguities efficiently within the regulatory framework of the basic services. It is additionally necessary to allow them to increase transparency in administrative procedures, to go forward with incentives regulation mechanisms, and to reach economies of scope in regulation.

\subsection{Resource Management Improvements}

The resource management system should be improved significantly in Chile. Clear and effective project evaluation criteria must be established to avoid discretionary decisions for approving concessions. Some important measures in this respect are providing permanent concessions to solar energy developers, allowing them to evaluate the project's commercial feasibility the in long-term; minimizing the number of secondary permissions required in concessionary grants; and controlling concessions agreements through incentives and penalties to avoid speculation problems. An effective SEIA should have an assessment methodology based on a range of alternatives, including different project sizes, sites, technologies, and mitigation strategies before deciding on a particular proposal. The scope of the risks and impacts identification process should be consistent with good international practices and should determine the appropriate and relevant methods and assessment tools. Each alternative should be evaluated earlier, more thoroughly and with more effective community engagement through 
disclosure of project-related information and consultation with local communities on matters that directly affect them.

\subsection{Improvements on Transmission Planning}

Chile is facing the urgent need to develop its transmission network infrastructure. Establishment of a comprehensive national transmission planning process are among the most urgent measures. In theory, the construction of transmission lines has significant economies of scale and investments in constructing new transmission lines are considered to be very risky [51] and [52]. To address this constraint, establishing coordinated "one-stop" siting process for renewable projects may solve the problem and make the projects feasible. In this context it is important to note that the cost structure of the transmission has important incentives for project coordination.

Another restriction is that a transmission project typically needs a high upfront investment, mostly on feasibility studies, environmental assessments and other preparatory activities. If a proposed project fails to acquire a site permit or is forced to cancel due to post-approval obstructions, these investments become financial losses. In order to reduce investors' risk in these matters, Chile may implement something similar as the European Union (EU) budget funds for pre-investment feasibility studies and other preparatory activities for transmission projects within which there is a potential national interest [53].

Transmission projects in Chile face huge risk of failure in obtaining site approval from multiple jurisdictions. There have been cases where transmission projects were cancelled due to continued local opposition even after site approval. In view of these serious difficulties in the transmission system, in 2013 the Chilean government approved the Electrical Easement Law 20,701 [32] with the aim of solving bottlenecks and problems detected in establishment of concise judicial proceedings. These mainly include the modification of the procedure for the appraisal of properties and resolution of conflicts among different types of concessions. Nevertheless, the implementation of this Law has been delayed until now and an avancement in this matter is the most urgent.

\section{Conclusions}

In recent years, solar power generation systems have gained significant attention as a key alternative to solve the energy problems in the world. Solar PV has come of age 
now that the technology has improved, the cost of PV solar panels has diminished significantly and the economies of PV technologies has become more significant and certain. Solar energy sources in Chile are the most dominant sources among the renewable energy resources. The country is endowed with one of the most consistently high solar potentials in the world. Electricity from solar energy it does not increase carbon dioxide emissions production and increases energy security. In addition, the high electricity prices and a large expected growth in energy demand for the upcoming years have been key blessing factors to be considered for the development of PV power sector in Chile. Over recent years, direct support mechanisms in Chile show good promise in providing a coherent framework which would significantly increase the share of solar PV within the electricity system. Despite the improvements in many areas, to date, numerous policy challenges exist. We have highlighted the key challenges in sustainable solar PV planning in Chile. Among them, we argued that three critical ones should be addressed: (i) market and institutional system, (ii) resources management, and (iii) transmission planning. Moreover, we propose improvement alternatives for challenges in existing solar PV planning conditions in Chile.

\section{References:}

[1] Declarations by OECD Member States on the accession of the Republic of Chile; OECD: Paris, France, 2009.

[2] World Bank. 2013. World Development Indicators, Chile.

[3] IEA, International Energy Agency,2012. Chile.

[4] National Energy Strategy 2012-2030; Ministero de Energia, Chile: 2012.

[5] Chile- Energy Policy Review; IEA, International Energy Agency: 2009.

[6] Varas, P., Tironi, M., Rudnick, H., and Rodríguez, N. 2013. The Growing Social Challenges of Hydroelectric Development. IEEE Power \& Energy Magazine

[7] Endesa, Chile. 2013. Annual Report

[8] Renewables 2014, Global Status Report; Renewable Energy Policy Network For The 21st Century (REN21): Paris, France, 2014 
[9] Haugwitz, F. China's Continuing Grid Curtailment Requires NEA to Strengthen its Supervision, Briefing Paper-China Solar PV Development. AECEA, 2014.

[10] Sener, C., Fthenakis,V. Energy policy and financing options to achieve solar energy grid penetration targets: Accounting for external costs. Renewable and Sustainable Energy Reviews 2014, 32 , 854-868.

[11] Timilsinaa,G.R, Kurdgelashvili,L., Narbel, P.A. Solar energy: Markets, economics and policies. Renewable and Sustainable Energy Reviews 2012, 16 , 449- 465.

[12] Design and performance of policy instruments to promote the development of renewable energy: emerging experience in selected developing countries; World Bank: Washington, DC, 2011.

[13] Solar generation VI-2011; Greenpeace and European Photovoltaic Industry Association: 2011.

[14] Unleashing the potential of renewable energy in India; World Bank: Washington, DC, 2011.

[15] Wiser R, Barbose G, Holt E. Supporting solar power in renewable portfolio standards: experience from the United States. Energy Policy 2010:3894-905

[16] Rowlands IH. Envisaging feed-in tariffs for solar photovoltaic electricity: European lessons for Canada. Renew Sustain Energy Reviews 2005:51-68.

[17] Frondel M, Ritter M, Schmidt C, et al. Economic impacts from the promotion of renewable energy technologies: the German experience. Energy Policy 2010;38(8):4048-56.

[18] Renewable Energy Policy Considerations For Deploying Renewables; International Energy Agency: OECD/IEA, France , Paris,2011.

[19] Díaz, C., Galetovic, A. and Soto, R. Anatomía de una Crisis Eléctrica. Revista de Análisis Económico 2011, 16(1) 3-57.

[20] Díaz, C., Galetovic, A. and Soto, R. La Crisis Eléctrica de 1998-1999: Causas, Consecuencias y Lecciones. Estudios Públicos 2010, 80: 149-92. 
[21] Galetovic, A., Inostroza J.R. and Muñoz, C. Gas y Electricidad: ¿Qué Hacer Ahora? Estudios Públicos 2004, 96: 49-106

[22] Nasirov, S. and Silva, C. Diversification of Chilean Energy Matrix: Recent Developments and Challenges. IAEE forum 2014, $4^{\text {th }}$ quarter.

[23] Speiser,R. Energy Security and Chile: Policy Options for Sustainable Growth. USAEE Working Paper,2008 No. 08-006.

[24] Zeballos, J. Challenges facing the mining industry. Sustainable Development in the Chilean Mining Industry, Round Table Chile-Denmark 2013.

[25] Román L. R and Vásquez, J. E. Solar Cogeneration: Integration between Energy and Mining. SERC-Chile 2014.

[26] Renewable Energy in Chile Moving towards a clean economical Moving towards a clean, economical \& secure energy matrix; CER: Santiago, Chile , 2014

[27] Tokman, R.M.The Energy Crisis and its Lessons: The Case of Chile. Ministry of Energy, 2009.

[28] Renewable Energy and Jobs Annual Review 2014;IRENA: 2014.

[29] Recommendations for Chile's Marine Energy Strategy - a roadmap for development; Aquatera:2014.

[30] Pastene,P. Solar Energy trends in a country with the highest solar radiation of the world. Fundacion Chile, 2014.

[31] Makrides G., Zinsser, B., Norton, M., Georghiou ,G.E., Schubert, M., Werner, J,H. Potential of photovoltaic systems in countries with high solar irradiation. Renewable and Sustainable Energy Reviews 2010;14(2):754-62.

[32] Energy Legislation; Central Energia : http://www.centralenergia.cl/regulacion/ 
[33] Non-Conventional Renewable Energy in the Chilean Electricity Market; CNE/GTZ: 2009

[34] Renewable Energy Project Status in Chile; CER: 2014.

[35] Law DFL No.1: General Law for Electric Services referring to Electric Energy; Mining Ministry of Chile: 1982.

[36 ] Pollitt, M. Electricity reform in Chile: Lessons for developing countries. The Center for Energy and Environmental Policy Research (CEEPR), University of Cambridge 2010.

[37] Susskind, L., Kausel, T., Aylwin, J., and Fierman, E. The Future of Hydropower in Chile. MIT, 2014 Working Paper.

[38] Basañes, C. F., Saavedra, E., Soto, R. Post-Privatization Renegotiation and Disputes in Chile. Inter-American Development Bank, 1999 Working Paper IFM \# 116.

[39] Arellano, M.S. Three Essays on Market Power in Chile's Electricity Industry. PhD Thesis submitted in MIT 2003.

[40] Saavedra, E. and Soto,R. Toward a Modern State in Chile: Institutions, Governance, and Market Regulation. Pontificia Universidad Católica de Chile, 2005 Documentos de Trabajo 277

[41] Thygesen, J. and Agarwal, A. Key criteria for sustainable wind energy planninglessons from an institutional perspective on the impact assessment literature. Renewable and Sustainable Energy Reviews 2014; 39: 1012-1023

[42] Jay S, Jones C, Slinn P, Wood C. Environmental impact assessment: retrospect and prospect. Environ Impact Assess Rev 2007;27:287-300.

[43] Jay S. Strategic environmental assessment for energy production. Energy Policy 2010;38:3489-97.

[44] Van Buuren A, Nooteboom S. The success of SEA in the Dutch planning practice. How formal assessments can contribute to collaborative governance. Environ Impact Assess Rev 2010;30:127-35. 
[45] Perez, D. and Cruz, F. Investment Guide Photovoltaics in Chile. PV Magazine 2013.

[46] PV in Chile - A Guide to Opportunities; PV Insider Latin America: 2013

[47] Oscar.M. Experience and new challenges in the Chilean generation and transmission sector .Energy Policy, 2007: 30: 575-582; 2007

[48] Araneda,J.C. and Valpuesta, R. Integrating renewable energy into the Chilean grid.Cigre ,2012.

[49] The Status of Renewable Electricity Mandates in the States; Institute for Energy Research: 2014

[50] Leyton,S. Chile Considers Bill to Boost Renewable Energy. Renewable Energy, 2012. http://www.renewableenergyworld.com/rea/news/article/2012/03/chile-considersbill-to-boost-renewable-energy.

[51] Jawaharlal Nehru National Solar Mission; the Ministry of New and Renewable Energy: 2012.

[51] Joskow, P., \& Tirole, J. Merchant transmission investment. The Journal of Industrial Economics ,2005. 53 (2), 223-264.

[52] Woolf, F. Global transmission expansion: recipes for success. Tulsa, Oklahoma: PennWell Corporation, 2003.

[53] Green paper: toward a secure, sustainable and competitive European energy network; European Commission: Brussels 2008. 